\title{
Evaluation of Pain Perception By Using Different Types of Separators - An Invivo Study
}

Shivaprasad $\mathrm{M}^{1}$, Vasu Murthy $\mathrm{S}^{2}$, Pavan Kumar $\mathrm{M}^{3}$, Praveen Kumar $\mathrm{N}^{4}$, Sreekanth $\mathrm{K}^{5}$, Harshanandan $\mathrm{B}^{6}$

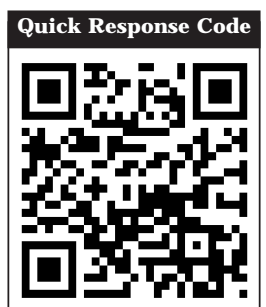

doi: $10.5866 / 2017.9 .10029$

1,5Senior Lecturer

${ }^{2}$ Professor \& HOD

${ }^{3}$ Professor

${ }^{4}$ Reader

${ }^{6}$ Post Graduate Student

Department of Orthodontics

Kamineni Institute of Dental Sciences

Sreepuram, Narketpally, Telangana State

\section{Article Info:}

Received: J anuary 11, 2017

Review Completed: February 12, 2017

Accepted: March 13, 2017

Available Online: March, 2017 (www.nacd.in)

(c) NAD, 2017 - All rights reserved

\section{Email for correspondence:}

drshivaprasad1988@gmail.com

\section{ABSTRACT:}

Context: Now a days two types of separators are commonly used, el astomeric and spring separators. The ideal separator should give rapid and good separation without causing the patient discomfort or pain, thereby making the fitting of the band to the tooth.

Aim: The preset study was carried out to evaluate pain perception by using two types of orthodontic separators namely elastomeric and kesling separators, focusing on patient's perception of pain and discomfort.

Materials and Methods: The separators tested were el astomeric and kesling separators ( 0.018 inch AJ Wilcock wire) forty subjects, who are scheduled for treatment with fixed orthodontic appliance were divided in to two groups. In selected subjects, kesling (0.018 inch SS wire) and elastomeric separators were placed alternately in the left and right quadrant of the maxillary arch and mandibular arch. After a period of 7 days, the pain experienced by the patient is analyzed by visual analogues scale.

Results: In all the groups, the pain was significantly reduced 7 days after the insertion of the separators. There is statistically significant difference present in the pain score according to the mean rank $(p=0.003)$ indicating that pain score is more in elastomeric group when compared to kesling group.

Conclusion: Kesling separators are more comfortable than elastomeric separators

Key words: Kesling separators, elastomeric separator, visual analogues scale.

\section{Introduction}

For treatment with a fixed orthodontic appliance, interproximal separation in between molars and premolars is necessary to create enough space for the bands that anchor the appliance. The ideal separator should give rapid and good separation without causing the patient discomfort or pain, thereby making the fitting of the band to 
the tooth. During the past 10 years, springs, brass wire and elastomerics have most often been used. ${ }^{1,2}$ If an orthodontic band measuring $0.15 \mathrm{~mm}$ thickness is placed around a tooth having an average periodontal ligament (PDL) space of $0.25 \mathrm{~mm}$ without proper separation, there is a risk of contacting the alveolar bone, producing hyalinization areas in the PDL and evoking pain response of resident mechanoreceptors. ${ }^{3}$

In a study by Hoffman, the separation effect of four types of separators was examined, but the patient's subjective experiences were not investigated. ${ }^{4}$ Perception of discomfort in patients undergoing orthodontic treatment, including 7 days of separation by elastomeric separators, was evaluated by Ngan et al. ${ }^{5}$ Davidovitch et al stated that elastomeric separators can achieve adequate separation in 8 to 12 hours depending on the tightness of contact point. ${ }^{6}$ However, in their study, they placed separators mesial to the first molars in the mandibular arch only. It has been reported that the contact point distal to first molar is tighter than the mesial. ${ }^{7.8}$

Two types of separators which are commonly used today are elastomeric and spring separators. Elastomeric are easily available and spring separators can be easily fabricated in the clinic.

The present study was undertaken to evaluate perception of pain with elastomeric and kesling separators in maxillary and mandibular arches and also focusing on the patients perception of pain and discomfort.

\section{Materials and Methods}

Forty patients who came to Orthodontics Department seeking orthodontic treatment (both male and female) ranging in age group 17 to 28 with no previous history of orthodontic treatment were selected for the present study. They all had permanent teeth erupted in both the arches except third molars. Contact tightness of first permanent molar with second premolar and second permanent molar was checked with the help of dental floss.

Two types of separators, i.e. elastomeric separators (Ortho Organizers) (Figurel) and kesling separators, made with 0.018" AJ Wilcock (Figure 2) wire using a bird beak plier by the orthodontist . ${ }^{9}$

Oral prophylaxis of all the patients was done prior to the placement of separators. The elastomeric separators $(E L)$ and kesling separators $(K P)$ were placed, at the mesial contact (MC) and distal contact (DC) of the first permanent molars in the maxillary arch (Mx) and mandibular arch (Md); with only one type of separator being placed on one side of each arch (Figure 3).

Elastomeric and kesling separators were placed alternately on the right or left side in each patient to avoid bias. Elastomeric separators were placed with a separator placing plier and the kesling separators with the light wire pliers. Patients were informed that separators may cause discomfort in the days following placement. They were instructed to take over-the-counter pain medication $(400 \mathrm{mg}$ I buprofen) as needed.

All the separators were removed on the followup appointments. All patients were asked to record their discomfort level on the follow-up appointment ranging from no discomfort to extreme discomfort according to the six points visual Analogous scale (VAS). ${ }^{10}$

Visual analog scale (VAS), each being $10 \mathrm{~cm}$ in length and weighted at both ends by descriptive terminology, e.g. 'no pain' vs 'pain as bad as it could be.. ${ }^{11}$ The patients were asked to mark the line at a point representing the severity of their pain, and the distance of the mark from the end of the scale was taken to represent pain severity.

The statistical analysis was done using SPSS version 22.0 statistical analysis software. Descriptive statistics, Man Whitney u test, Friedman chi-square test were done.

\section{Results:}

All 40 subjects completed the study and the response rate was excellent, since all patients responded to all questions. The baseline survey, before separator placement, revealed that none of the patients had any pain in the maxillary first molars when chewing. 
In all the groups, the pain was significantly reduced 7 days after the insertion of the separators (Table 1) (Figure 4). It is evident that the most comfortable separators on chewing, biting, fitting your back teeth together, fitting your front teeth together, feeling about self and speech were the Kesling separators.

Theinsertion and removal of Kesling separators was extremely simple but sometimes difficulty might beencountered during removal of Kesling separators if they are rotated. Elastomeric separators were easy to remove but extreme force was required during their placement. At times they even broke during insertion. At day 7 there is statistically significant difference present in the pain score according to the mean rank ( $p=0.003$ ) which indicates that pain score is more in elastomeric group when compared to kesling group.

\section{Discussion}

It was found that the patients had experienced a range of pain from mild to moderateintensity with both kesling separator and elastomeric separators during the separation period. This finding is in accordance with the previous study by J ones ML, wherethere is varying degree of individual pain and discomfort in response to application of orthodontic forces. ${ }^{12}$ Although elastomeric separators are more painful than the kesling separators, the difference were statistically significant $(p \varangle 0.01)$.

The pain intensity was higher on chewing as compared to rest, especially on day two for kesling separator and elastomeric separator. In the present study evaluation of pain was performed using a VAS and patients were asked to rate their pain intensity choosing from the following descriptors: $\mathrm{N}$ one (0), very mild (1), mild (2), moderate (3), severe (4) and very severe (5).

The VAS was used to measure pain intensity, since it is one of the most commonly used tools to measure pain and discomfort intensity and is easy to administer and score. It is also a valid and reliable method of measuring discrete pain, being able to discriminate pain intensity. It had been also found that the VAS is a useful tool when patients have to discriminate between pain in the Posterior and anterior teeth after initial placement of an archwire. Therefore, VAS was the choice of pain assessment tool in our study for evaluating pain in the left and right posterior teeth on chewing and rest when two different separators were placed blindly on theright and left side respectively, similar to the study carried out by Bondemark et al. ${ }^{13}$

The pain perceived by the subjects was worst on day 2 and declined on the following day, i.e. day 3. This is well in accordance with the study conducted by Bondemark but contrary to the findings reported by Bernhardt et al and Bergius et al who found pain to be worst after day 1 of elastomeric separators placement and then declining gradually by day $3 .^{13-15}$ On comparing the intensity of pain resulted after placement of elastomeric separators with that after placement of kesling separators no difference was found in the intensity of pain on VAS scale on all days.

The varying degree of individual pain/ discomfort response to application of orthodontic forces has previously been reported and this tends to be confirmed in this study. It was found that mild to moderate pain was associated with all orthodontic separators. However, the most comfortable separators on chewing, biting, fitting your back teeth together, fitting your front teeth together, feeling about self and speech were the Kesling separators. These findings are in accordance with those found by $L$ Bondemark and Iiros who stated that elastomeric separators cause more pain than Kesling separators. ${ }^{13}$ However, our results corresponded with the clinical trial conducted by Hoffman where elastomeric separators caused more pain than kesling separators. ${ }^{16}$

Patient complaints with different separators are as follows:

Kesling separators: Discomfort during chewing, irritated the tongue, one patient devel oped ulceration on the tongue, difficult to brush and painful sometimes.

Elastomeric separators: Extremely uncomfortable on chewing, very painful and most of them experience pain. 


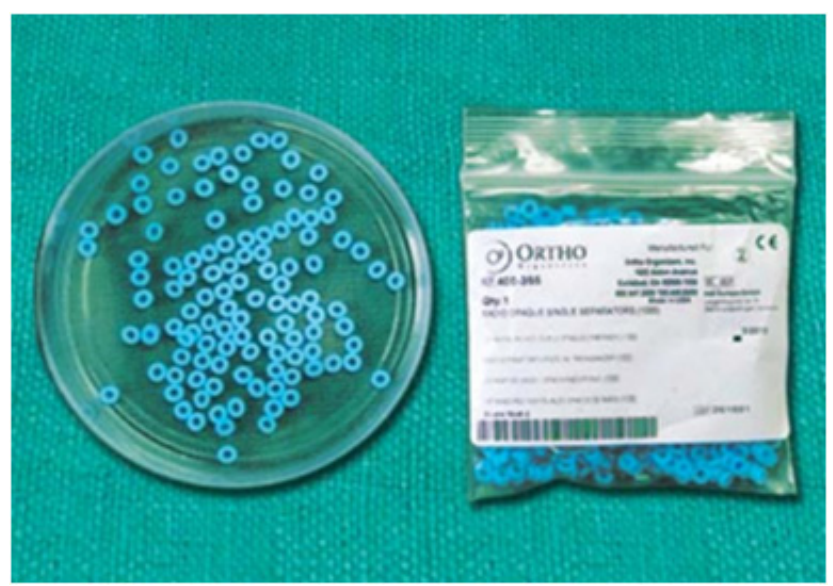

Figure 1: Elastomeric separators

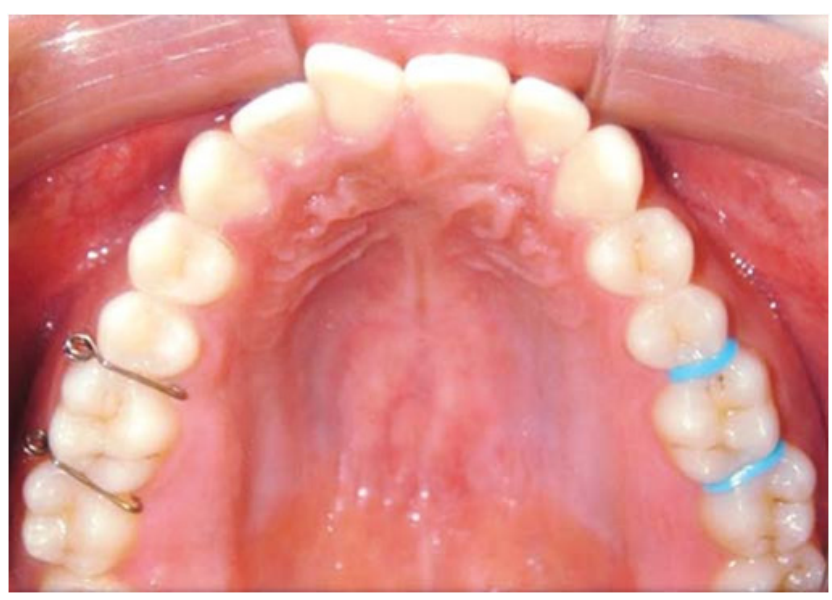

Figure 3: Placement of separators at mesial and distal contacts of permanent first molars in maxillary and mandibular arches

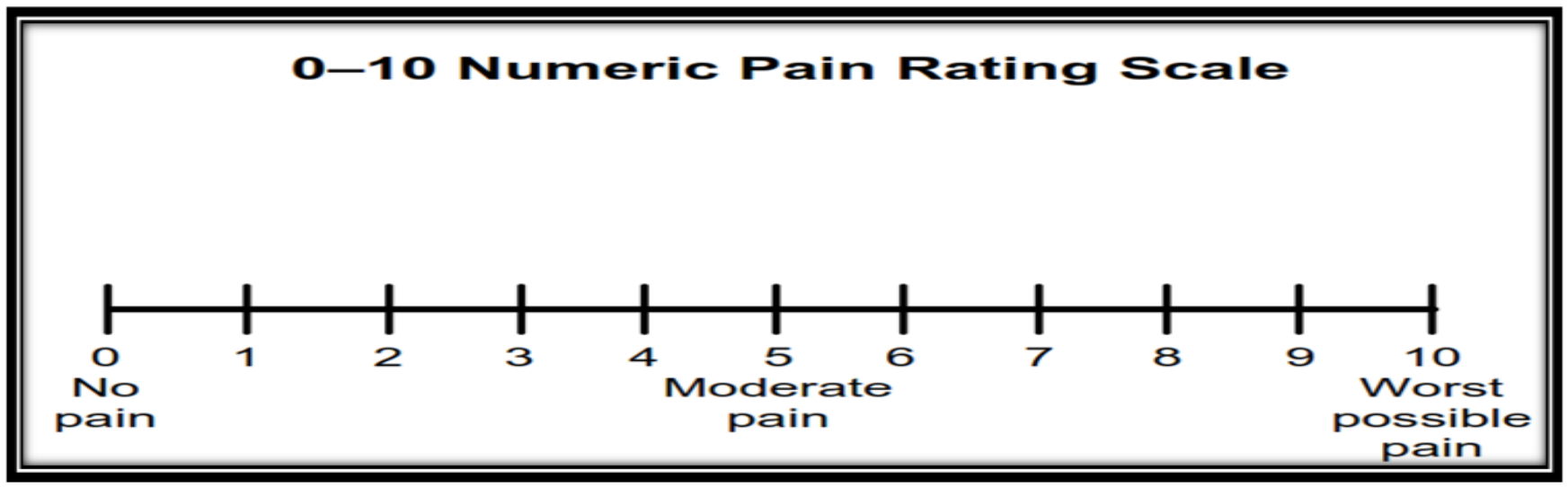

Figure 4: Numeric pain rating scale

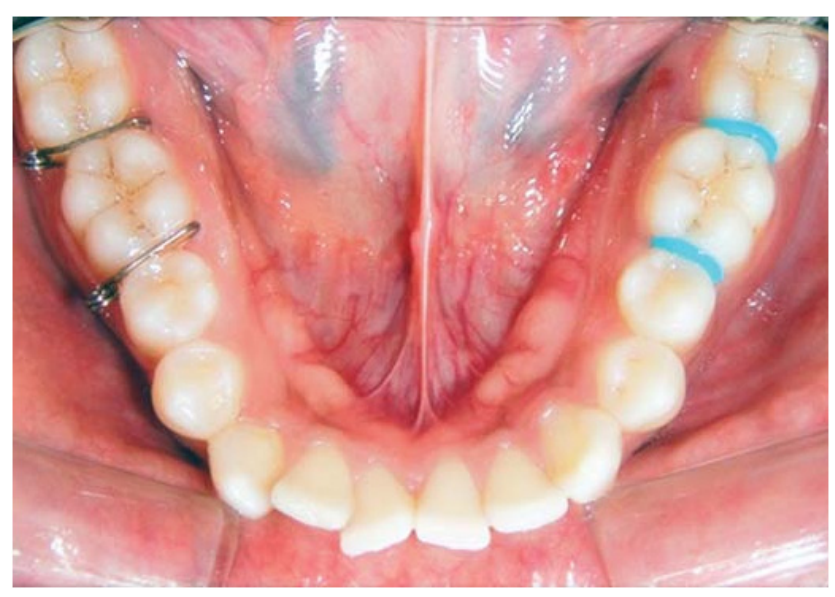

Figure 2: Kesling separators 


\section{PAIN MEASUREMENT SCALE}

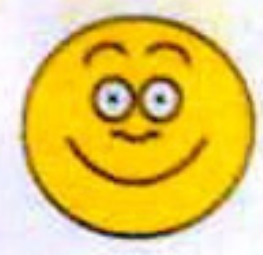

0

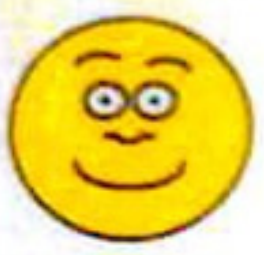

2

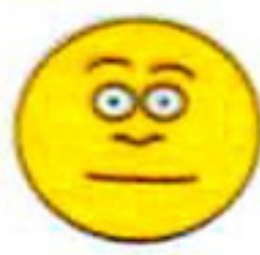

4

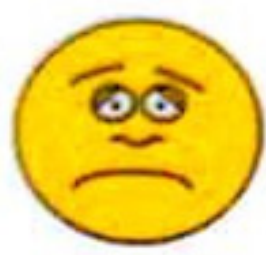

6

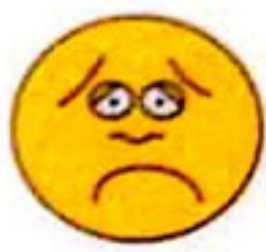

8

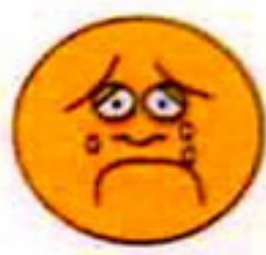

10

NO HURT

HURTS

HURTS

HURTS

LITTLE BIT LITTLE MORE EVEN MORE

HURTS

HURTS

WORST

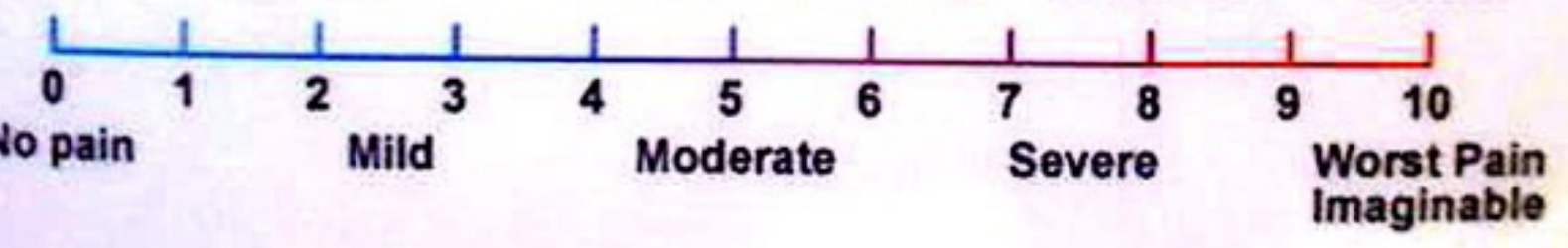

Figure 5: Visual analog scale

Table 1: Comparison of pain scores at various time periods in both the groups showing statistically significant difference present in the pain score $(p=0.003)$, indicating that pain score is more in elastomeric group when compared to kesling group.

\begin{tabular}{|c|c|c|c|c|c|c|}
\hline \multirow[t]{2}{*}{ Groups } & \multicolumn{2}{|c|}{ Day 1} & \multicolumn{2}{|c|}{ Day 7} & \multirow{2}{*}{$\begin{array}{l}\text { Chi sq } \\
\text { value }\end{array}$} & \multirow[t]{2}{*}{ p value } \\
\hline & Median & $\begin{array}{l}\text { Mean } \\
\text { Rank }\end{array}$ & Median & $\begin{array}{l}\text { Mean } \\
\text { Rank }\end{array}$ & & \\
\hline Elastomeric Separator & 6 & 1.99 (58.94) & 2 & $1.01(50.77)$ & 42 & $\measuredangle 0.001 * *$ \\
\hline Kesling Separator & 4 & $1.94(28.06)$ & 2 & $1.06(36.23)$ & 36.1 & $\varangle 0.001^{* *}$ \\
\hline$Z$ value & -5.902 & -2.996 & & & & \\
\hline p Value & $\varangle 0.001^{* *}$ & $0.003^{* *}$ & & & & \\
\hline
\end{tabular}

As it has been well documented in literature, perception of same threshold of pain is interpreted differently by different patients as pain is a subjective, multidimensional sensation. It implies that one cannot standardize the amount of pain felt by a person, so is the case after administration of an analgesic. This was one reason why administration of same dosage of analgesic was excluded from the standardization criteria of our sample.

All patients were advised to take over-thecounter pain medication (400mg I buprofen), if required. 


\section{Conclusion}

Kesling separators are causing consi derably less discomfort than that with elastomeric separators. The insertion of elastomeric separators is more difficulty while the placement and removal of Kesling was simple and there was no food lodgment and also the oral hygiene was easily maintained by elastomeric separators and Kesling separators.

\section{References}

1. McNamara J A J r. Ordinary orthodontics: Starting with the end in mind. World J Orthod 2000; 1:45-54.

2. Proffit WR. Contemporary Orthodontics (2nd ed). St Louis: Mosby 2000: 392-94.

3. Proffit WR. Contemporary orthodontic appliances. In: Proffit WR, Fields HW, Sarver DM, editors. Contemporary Orthodontics. 4th ed. St Louis: Mosby; 2007; 412-13.

4. Hoffman WE. A study of four types of orthodontic separator. Am J Orthod 1972; 62:67-73.

5. Ngan P, Wilson S, Shanfeld J, Amini H. The effect of ibuprofen on the level of discomfort in patients undergoing orthodontic treatment. Am J Orthod Dentofacial Orthop 1994; 106:88-95.

6. Davidovitch M, Papanicolaou S, Vardimon AD, Broshd T. Duration of elastomeric separation and effect on interproximal contact point characteristics. Am J Orthod Dentofacial Orthop 2008; 133:414-22.

7. Southard TE, Behrents RG, Tolley EA. The anterior component of occlusal force. Part 1. Measurement and distribution. AmJ Orthod Dentofacial Orthop 1989; 96:493500.
8. Vardimon AD, Matsaev E, Lieberman M, Brosh T. Tightness of dental contact points in spaced and nonspaced permanent dentitions. Eur J Orthod 2001; 23:305-14.

9. Begg PR, Kesling PC. Orthodontic appliances. In: Begg PR, Kesling PC (Eds). Begg orthodontic theory and technique. 3rded. Philadel phia, PA: WB Saunders; 1977; 87-141.

10. Visual Analog Scale and Verbal Pain Intensity Scale: From Pain Management: Theory and Practice, edited by RK Portenoy \& RM Tanner, copyright 1996 by Oxford University Press, Inc. Used by permission of Oxford University Press.

11. Scott J , Huskisson EC. Graphic representation of pain. Pain 1976; 2:175-84.

12. J ones ML. An investigation into theinitial discomfort caused by placement of an archwire. Eur J Orthod.1984;6:48-54n P, Kess B, Wilson S. Perception of discomfort by patients undergoing orthodontic treatment. AmJ Orthod Dentofacial Orthop 1989; 96:47-53.

13. Bondemark L, Fredriksson K, I Iros S. Separation effect and perception of pain and discomfort from two types of orthodontic separators. World J Orthod 2004; 5:172-76.

14. Bernhardt MK, Southard KA, Batterson KD, Logan HL, Baker KA, J akobsen J R. The effect of preemptive and/or postoperative ibuprofen therapy for orthodontic pain. Am J Orthod Dentofacial Orthop 2001; 120:20-27.

15. Bergius $M$, Berggren $U$, Kiliaridis S. Experience of pain during an orthodontic procedure. Eur J Oral Sci 2002; 110:92-98.

16. H offman WE. A study of four types of orthodontic separator. Am J Orthod 1972; 62:67-73.

\section{Gain quick access to our journal online View our journal at www.nacd.in}

